\title{
Comments on "A Physical Study of Solid Precipitation from Convective Clouds over the Sea : Part I"
}

\author{
by S. Tsunogai \\ Department of Chemistry, Faculty of Fisheries, Hokkaido University \\ and 0 . Matsubaya \\ Department of Chemistry, Faculty of Science, Tokyo Kyoiku University \\ (Received 12 January 1967)
}

In the June 1966 issue of this journal, Isono et al. (1966) tried to estimate the temperature of the sea surface from which water of snowfall has evaporated, by using the variation of deuterium concentration in snow water. It is useful to apply the isotopes of water to the meteorological problems and we hope such attempts will be much more developed. However, the conclusion of this paper seems to be doubtful because their discussions are not so strict. We wish to point out these uncertain points.

(1) Isono et al. used a model concerning the process of the formation of cloud and precipitation which had been devised by Facy et al. (1963). About this model, we have three questions.

At first, in this model snow crystals behave together with water vapor in the same air parcel up to the final stage of snow formation. If this is true, cloud water content of $3 \mathrm{~g} / \mathrm{m}^{3}$ of air must be observed. Moreover, it may be difficult to assume the isotope equilibrium between the residual water vapor and the interior of solid crystals.

In the next place, the deuterium content of snow cannot be lower than that of original water vapor so far as their model is used. Miyake and Matsubaya (1966), however, observed such light snow. This may be considered as the fractional separation of isotopes between cloud droplets and water vapor.

In the third, it is essential in their model that all of the water vapor from which snow is formed is evaporated from the surface of the Japan Sea under the isotopic equilibrium state. Ninomiya (1964) and Fujita and Honda (1966) reported that the amount of water vapor transported from the Continent is com- parable with that evaporated from the Japan Sea.

(2) Isono et al. obtained the mean values and ranges of the mean error of deuterium content from analytical values which have large errors. Their statistical treatment seems to be erroneous. They used $\sigma / \sqrt{N}$ as the mean error where $\sigma$ is the square root of unviased variance of the population and $N$ is the number of samples. $\sigma / \sqrt{N}$ means only the standard deviation of the sample mean from the population mean. For these discussions, we must use $\sigma$ itself as the measure of uncertainty as far as the normal distribution can be assumed.

Furthermore, we do not know the value of $\sigma$, the standard deviation of the population, and cannot calculate it from their data. The figure, $\pm 5 \mathrm{ppm}$, used as $\sigma$ by Isono et al. is not the real $\sigma$ but the analytical error of one sample. Miyake and Matsubaya (1966) observed the daily variation of oxygen-18 content in snow. This suggests that the standard deviation $\sigma$ of deuterium content in snow with the same crystal shape may be comparable with the variation of deuterium content in water vapor according to the variation of sea surface temperature. In any case, the sum of $\sigma$ and the analytical error may be much larger than the ranges used by them.

(3) Isono et al. gave 145-148 ppm for four observation stations as the mean deuterium content and discussed the differences among these means. These values fall within the limits of analytical error. The surface water temperature deduced from these values has much error and we cannot decide where water vapor originated.

(4) Isono $e t a l$. attributed the small $D / H$ 
ratios of rimed snow crystals to the thickness of cloud through which the snow fell. However, the deuterium content in snow is not to be related with the thickness of cloud. For, according to their assumption about the model of snow formation and the meteorological conditions in winter in Japan, the deuterium content of the snow is due only to the final temperature of growth.

On the other hand, if the deuterium content of snow is changed by the captured cloud drops, the snow will increase its deuterium content owing to the high deuterium content of the supercooled cloud drops which was formed in lower layer and at higher air temperature.

(5) The probable sea surface temperature is not always determined for each rainfall by the deuterium content of a snow crystal and the temperature at the end of its growth so far as their model is used. For instance, in the case of non-rimed snow crystals, the evaporation temperature turns out to be $+15^{\circ} \mathrm{C}$, which is higher than the surface temperature of any part of the Japan Sea. It is necessary that the same sea surface temperature can be obtained even in the case of the different crystal shape. This suggests that their model of snow formation is not a real one.

(6) The temperature of surface water of the Japan Sea used by Isono et al. is the average of observed data for long years. In the Japan Sea, the Tsushima Warm Current is bounded sharply by cold waters and changes the direction of the stream from time to time. The isotherm of the surface temperature at a certain time may be greatly different from that used by Isono et al.

(7) To estimate the sea water temperature within the limits of error of $\pm 1^{\circ} \mathrm{C}$, the accurate measurements are necessary, of which limit of analytical error is $\pm 0.2 \mathrm{ppm}$ for deuterium content in snow, $\pm 0.5^{\circ} \mathrm{C}$ for final temperature of growth of snow crystals and $\pm 0.5^{\circ} \mathrm{C}$ for temperature at condensation level. It is not so easy to carry out these measurements within the above mentioned limits of error.

We will discuss the meteorological applications of stable isotopes of water after the accurate data are obtained.

\section{References}

Facy, L., L. Merlivat, G. Nief and E. Roth, 1963 : The study of the formation of a hailstone by means of isotopic analysis. J. Geophys. Res., 68, 3841-3848.

Fujita, T. and T. Honda, 1965: Observational estimation of evaporation and sensible heat transfer from the Japan Sea in winter. Tenki, 12, 204-213.

Isomo, K., M. Komabayashi and T. Takahashi, 1966: A physical study of solid precipitation from convective clouds over the sea : Part IDeuterium content of snow crystals with respect to crystal shapes and their relation to origins of the water vapour of snowfall. $J$. meteor. Soc. Japan, 44, 178-184.

Miyake, Y. and O. Matsubaya, 1966: Paper presented at Meeting of Meteor. Soc. Japan in Sapporo, Oct. 1966.

Ninomiya, K., 1964: Water substance budget over the Japan Sea and the Japan Islands during the period of heavy snow storm. J. meteor. Soc. Japan, 42, 317-329. 